\title{
The resistive and elastic work of breathing during exercise in patients with chronic heart failure
}

\author{
Troy J. Cross,*,ף, Surendan Sabapathy ${ }^{\#, \oplus, ~ K e n n e t h ~ C . ~ B e c k *, ~ N o r m a n ~ R . ~ M o r r i s *, \#, ~}$ \\ and Bruce D. Johnson*
}

ABSTRACT: Patients with heart failure (HF) display numerous derangements in ventilatory function, which together serve to increase the work of breathing $\left(W_{b}\right)$ during exercise. However, the extent to which the resistive and elastic properties of the respiratory system contribute to the higher $W_{b}$ in these patients is unknown.

We quantified the resistive and elastic $W_{b}$ in patients with stable HF $(n=9$; New York Heart Association functional class I-II) and healthy control subjects $(n=9)$ at standardised levels of minute ventilation $\left(V^{\prime} E\right)$ during graded exercise. Dynamic lung compliance was systematically lower for a given level of $V^{\prime} E$ in HF patients than controls $(p<0.05)$. HF patients displayed slightly higher levels of inspiratory elastic $W_{b}$ with greater amounts of ventilatory constraint and resistive $W_{b}$ than control subjects during exercise $(p<0.05)$.

Our data indicates that the higher $W_{b}$ in HF patients is primarily due to a greater resistive, rather than elastic, load to breathing. The greater resistive $W_{b}$ in these patients probably reflects an increased hysteresivity of the airways and lung tissues. The marginally higher inspiratory elastic $W_{b}$ observed in HF patients appears related to a combined decrease in the compliances of the lungs and chest wall. The clinical and physiological implications of our findings are discussed.

KEYWORDS: Heart failure, respiratory mechanics, work of breathing

$\mathbf{T}$ he capacity to perform exercise is often severely reduced in patients with heart failure (HF) [1-3]. These patients typically display a blunted cardiac output response to exercise concomitant with derangements in ventilatory function, including gas-exchange abnormalities, obstructive-restrictive lung disorders, decreased lung compliance, etc. [4-7]. Accordingly, the energetic demands of exercise for HF patients may be compounded by an inordinately high work of breathing $(\mathrm{Wb})$ for a given level of minute ventilation $\left(V^{\prime} \mathrm{E}\right)$ and external work $[8,9]$. This heightened $\mathrm{Wb}$ necessitates greater oxygen delivery to the respiratory muscles, potentially at the expense of oxygen supply to the locomotor muscles, impairing the patient's ability to perform muscular work $[10,11]$. Indeed, exercise capacity increases in these patients when the $W_{b}$ is unloaded via assisted ventilation or by breathing reduced-density gases $[12,13]$. It can then be reasoned that an elevated $\mathrm{Wb}$ contributes to the development of exertional fatigue in HF. Despite this rationale, there exists no systematic quantification of the $W \mathrm{~b}$ across the range of $V^{\prime}$ E experienced by HF patients during dynamic exercise.

Pulmonary function in HF patients is typified by an overall restrictive lung disorder that is secondary to an increase in the elasticity of lung tissues, and/or a decreased ability to inflate the lungs due to an enlarged heart (i.e. cardiomegaly) [14-18]. In addition, there is cause to believe that resistance of the airways and lung tissues is greater in HF patients compared with healthy, age-matched individuals at rest and during exercise $[19,20]$. Such ventilatory derangements, in these patients, would serve to increase the amount of respiratory muscle work required to achieve and maintain a given tidal volume $(V \mathrm{~T})$ and respiratory frequency $(f \mathrm{R})$, thereby changing the pattern of breathing observed during exercise. Although many investigators appreciate that the resistance and elastance of the respiratory system are greater in this population, it is uncertain to what extent these parameters contribute to the overall higher $\mathrm{Wb}$ anticipated in these patients at a given level of $V^{\prime} E$ during exercise.

\section{AFFILIATIONS}

*Division of Cardiovascular Diseases, Mayo Clinic, Rochester, MN, USA. \#Griffith Health Institute, and "School of Physiotherapy and Exercise Science, Griffith University, Southport, Australia.

CORRESPONDENCE

T.J. Cross

School of Physiotherapy and

Exercise Science

Gold Coast Campus

Griffith University

Southport 4222

Australia

E-mail: t.cross@griffith.edu.au

Received:

July 222011

Accepted after revision:

Oct 102011

First published online:

Oct 272011 
The aims of the present study were to quantify the resistive and elastic components of the $W b$ in patients with stable HF and healthy, age-matched individuals at standardised levels of $V^{\prime} \mathrm{E}$ during graded exercise. It was hypothesised that HF patients would display greater amounts of resistive and elastic respiratory muscle work at each level of $V^{\prime} \mathrm{E}$ than control subjects. Currently, there are no specific guidelines for the management of respiratory symptoms in HF. The findings of this study may, therefore, aide in the improvement of existing treatment strategies for these patients, and/or indicate other therapeutic targets to consider in the clinical management of this population.

\section{MATERIALS AND METHODS}

\section{Subjects and ethical approval}

Nine patients with a history of HF and nine healthy, agematched control subjects volunteered to participate in the present study. The HF patients recruited for the study were required to meet the following criteria: 1 ) $a \geqslant 1$-yr history of known HF; 2) New York Heart Association (NYHA) functional class I, II or III symptoms; 3) an ejection fraction $\leqslant 35 \%$ measured by echocardiography; 4) no history of dangerous cardiac arrhythmias; 5) no pacemakers; and 6) at least one prior hospitalisation due to HF. All patients were receiving standard, optimised pharmacotherapies for the management of HF at the time of the study. The age-matched control subjects were recruited from the surrounding community and were current nonsmokers (past 15 yrs) with no history of cardiac or pulmonary diseases. Participants were excluded from the study if their body mass index (BMI) was $\geqslant 35 \mathrm{~kg} \cdot \mathrm{m}^{-2}$ and /or reported a smoking history $>15$ pack-yrs. All participants provided written informed consent to participate in the study, which had been approved by the Institutional Review Board of the Mayo Clinic and Foundation (Rochester, MN, USA). Each subject had been exposed to formal exercise testing on at least one prior occasion, i.e. all individuals were familiar with the exercise mode of cycle ergometry.

\section{Graded exercise test}

All subjects performed a graded exercise test to volitional exhaustion on an electronically braked upright cycle ergometer (Lode Corival, Groningen, the Netherlands). The graded exercise protocol commenced with 2 min of unloaded cycling, after which the power output was increased every $2 \mathrm{~min}$ by $20 \mathrm{~W}$ (for HF patients) or $30 \mathrm{~W}$ (for control subjects). A self-selected pedal cadence (60-70 revolutions per minute) was maintained by each subject until exhaustion. Cardiac rhythm and heart rate were monitored continuously during the graded exercise test. Each individual reported a rate of perceived exertion score of 18-20 at volitional exhaustion. Pulmonary gas exchange was determined breath by breath via mass spectrometry (model 1100; PerkinElmer, Waltham, MA, USA) and a bidirectional differential pressure pneumotachograph (preVent $\mathbb{R}$; Medical Graphics Corporation, St Paul, MN, USA) while wearing a nose clip. Peak values are reported as the average of the final $60 \mathrm{~s}$ of graded exercise.

\section{Respiratory pressures}

Oesophageal pressure (Poes) was measured using a latex balloon-tip catheter (CooperSurgical Inc., Trumbull, CT, USA) that was inserted via the nose to $\sim 45 \mathrm{~cm}$ distal to the nares. The balloon-tip catheter was inflated with $1 \mathrm{~mL}$ of air and the occlusion test [21] was performed to ensure correct placement (i.e. lower one-third of the oesophagus). Mouth pressure (Pmo) was sampled via a lateral port in the mouthpiece. The catheters were connected to differential pressure transducers (MP45; Validyne Engineering Corporation, Northridge, CA, USA), which were calibrated using a water manometer before each test.

\section{Respiratory mechanics}

Before and immediately after the graded exercise test, subjects performed seven to 10 vital capacity manoeuvres with varying degrees of effort (i.e. 20-100\% of maximal effort). These efforts defined the maximal inspiratory and expiratory flow-volume envelopes for each subject, with minimal artefacts due to thoracic gas compression [22]. Subjects were also instructed to perform maximal inspiratory manoeuvres to determine inspiratory capacity (IC) while at rest and two to three times towards the end of each minute during graded exercise. All pulmonary function tests were performed while seated on the cycle ergometer. The methods used to estimate maximal ventilatory capacity (MVC) were modified from those described by others $[23,24]$. The degree of expiratory flow limitation during exercise was assessed by comparing the subject's exercise tidal flow-volume loop with their maximal volitional flow-volume envelope and by determining the subject's maximal effective expiratory pressures using the isovolume pressure-flow technique [25]. Static recoil pressure of the chest wall was measured before graded exercise using the quasistatic relaxation technique [26]. The components of the $\mathrm{Wb}$ were quantified using modified Campbell diagrams constructed from flow, pressure and volume data obtained during graded exercise [27]. The reader is directed to the online data supplement for a detailed description of the above methodological procedures.

\section{Data analysis}

The analogue signals of the mass spectrometer and pneumotachograph, Pmo, and Poes were digitised at $100 \mathrm{~Hz}$ (PCI-DAS6034; Measurement Computing Corporation, Norton, MA, USA), and subsequently analysed with custom-written software to provide breath-by-breath indices of pulmonary gas exchange and respiratory mechanics. All indices of respiratory mechanics were averaged into bins corresponding to a $V^{\prime} \mathrm{E}$ of $20,40,60$ and $80 \mathrm{~L} \cdot \mathrm{min}^{-1}$.

\section{Statistical analyses}

The subject characteristics, pulmonary function and peak exercise data were compared between groups using unpaired t-tests. The differences between groups for all measures of respiratory mechanics at standardised $V^{\prime} \mathrm{E}$ during graded exercise were evaluated using a two-way mixed-factor ANOVA. Given that obesity (specifically, visceral fat mass) is known to influence respiratory mechanics during exercise [28], subjects' body mass was entered into the ANOVA model as a covariate. For the majority of parameters, body mass was not a significant covariate. When body mass was identified as a significant covariate in the ANOVA model, it did not change the overall differences observed between groups for the corresponding parameter. Statistical analyses were considered significant if $\mathrm{p}<0.05$. All values are reported as mean \pm SEM.

\section{RESULTS}

\section{Subject characteristics and peak exercise data}

Two HF patients were NYHA class I and the remaining seven patients were NYHA class II. The mean ejection fraction of HF group was $32 \pm 1 \%$. The HF patients were taking combinations 
of angiotensin-converting enzyme inhibitors $(n=9)$, diuretics $(n=6)$, anti-arrhythmic agents $(n=4)$, statins $(n=6)$, nonselective adrenergic receptor blockers $(n=8)$ and $\beta_{1}$-adrenergic receptor blockers $(n=2)$. None of the control subjects were taking prescription medications for cardiovascular, metabolic or pulmonary diseases at the time of the study.

The subjects' physical characteristics, pulmonary function and peak exercise values are presented in table 1 . Two healthy control subjects and four HF patients reported a positive smoking history; all other participants reported no smoking history. There were no group differences for age and height, although body mass and BMI were significantly greater for patients with HF than control subjects $(p<0.05)$. HF patients exhibited significantly lower values for forced vital capacity (FVC), forced expiratory volume in $1 \mathrm{~s}$ (FEV1), FEV1/FVC, peak expiratory flow rate and forced expiratory flow at $25-75 \%$ of FVC when compared with control subjects $(p<0.05)$. However, the predicted values for the above parameters in HF patients were, on average, toward the lower end of the normal range. Nevertheless, these results indicate a greater degree of lung restriction and airway obstruction in $\mathrm{HF}$ patients relative to the healthy, age-matched individuals of the present study. While resting IC was not different between groups, end-expiratory lung volume (EELV) at rest was significantly lower in patients with HF compared with the control group $(\mathrm{p}<0.05)$. The chest wall compliance of $\mathrm{HF}$ patients $\left(150 \pm 30 \mathrm{~mL} \cdot \mathrm{cmH}_{2} \mathrm{O}^{-1} ; 99 \pm 6 \%\right.$ predicted) was significantly lower when compared with control subjects $\left(182 \pm 38 \mathrm{~mL} \cdot \mathrm{cmH}_{2} \mathrm{O}^{-1} ; 109 \pm 6 \%\right.$ pred $)(\mathrm{p}<0.05)$. On average, maximal oxygen uptake, work rate, $V^{\prime} \mathrm{E}$ and cardiac frequency were significantly lower for patients with HF compared with healthy control subjects $(\mathrm{p}<0.05)$ and predicted scores.

\section{Respiratory mechanics}

The pattern of breathing during graded exercise for HF patients and control subjects is reported in table 2 . In comparison with control subjects, patients with HF demonstrated a more pronounced tachypnoea, evidenced by their smaller $V \mathrm{~T}$ and faster $f R$ toward higher levels of $V^{\prime} E(p<0.05)$. The higher $f R$ values observed in HF patients were primarily due to significantly shorter inspiratory times compared with control subjects $(\mathrm{p}<0.05)$. Mean inspiratory flows were not different between groups during graded exercise. However, mean expiratory flows for HF patients were marginally slower than those of control subjects at $V^{\prime} \mathrm{E} 40$ and $60 \mathrm{~L} \cdot \mathrm{min}^{-1}(\mathrm{p}<0.05)$.

The progression of ventilatory constraint during graded exercise in HF patients and control subjects is illustrated in figure 1. At each level of $V^{\prime} E$, HF patients exhibited a greater degree of expiratory flow limitation and their exercise flow-volume loops occupied a greater proportion of maximal achievable flow rates (i.e. MVC) compared with the control subjects $(\mathrm{p}<0.05)$. Dynamic lung volumes obtained during graded exercise are presented in figure 2. The dynamic lung volumes of HF patients were systematically lower compared with control subjects at each level of $V^{\prime} \mathrm{E}(\mathrm{p}<0.05)$. For the control group, EELV was significantly higher than resting values (i.e. dynamic hyperinflation) at levels of $V^{\prime} \mathrm{E}>60 \mathrm{~L} \cdot \mathrm{min}^{-1}(\mathrm{p}<0.05)$. Mean values for EELV of HF patients were systematically higher than resting values throughout graded exercise $(\mathrm{p}<0.05)$. Dynamic lung compliance $\left(\mathrm{C}\right.$,dyn) was significantly lower in HF patients at levels of $V^{\prime} \mathrm{E}$ corresponding to 20, 40 and $60 \mathrm{~L} \cdot \mathrm{min}^{-1}$. There appeared an appreciable, albeit nonsignificant, difference in $\mathrm{C} L$,dyn between $\mathrm{HF}$ patients and control subjects at a $V^{\prime} \mathrm{E}$ of $80 \mathrm{~L} \cdot \mathrm{min}^{-1}$ $\left(264 \pm 26 \mathrm{~mL} \cdot \mathrm{cmH}_{2} \mathrm{O}^{-1}\right.$ versus $\left.333 \pm 43 \mathrm{~mL} \cdot \mathrm{cmH}_{2} \mathrm{O}^{-1} ; \mathrm{p}=0.09\right)$.

The relationships between the total $\mathrm{Wb}$ and $V^{\prime} \mathrm{E}$ during graded exercise are presented in figure 3 . The total $W b$ was higher at given level of $V^{\prime} \mathrm{E}$ for patients with HF compared with control subjects during graded exercise $(\mathrm{p}<0.05)$. The resistive and elastic components of the $\mathrm{Wb}$ during graded exercise are shown in figure 4. In general, the inspiratory and expiratory resistive $\mathrm{Wb}$ was systematically higher in patients with HF compared with control subjects at each level of $V^{\prime} E$ investigated $(p<0.05)$. Inspiratory elastic $W \mathrm{~b}$ was significantly higher for HF patients than control subjects at a $V^{\prime} \mathrm{E}$ of 40 and $60 \mathrm{~L} \cdot \mathrm{min}^{-1}(\mathrm{p}<0.05)$. There were no consistent differences between groups for the expiratory elastic work at each level of $V^{\prime} \mathrm{E}(\mathrm{p}>0.30)$.

\section{DISCUSSION}

The major findings of the present study were that patients with stable HF are faced with an inordinately higher $W_{b}$ compared with healthy, age-matched subjects for a given level of $V^{\prime} \mathrm{E}$.

\begin{tabular}{|c|c|c|c|c|}
\hline & \multicolumn{2}{|c|}{ Control } & \multicolumn{2}{|l|}{ HF } \\
\hline & Measured & $\%$ pred & Measured & $\%$ pred \\
\hline Age yrs & $55 \pm 4$ & & $57 \pm 4$ & \\
\hline Height cm & $179 \pm 2$ & & $180 \pm 2$ & \\
\hline Body mass kg & $86.4 \pm 2.4$ & & $103.8 \pm 4.1^{*}$ & \\
\hline BMI $\mathbf{k g} \cdot \mathrm{m}^{-2}$ & $26.4 \pm 0.9$ & & $32.3 \pm 0.9^{*}$ & \\
\hline Aetiology n & & & $4 \mathrm{IDC} / 5 \mathrm{CAD}$ & \\
\hline Smoking history pack-yrs & $1.9 \pm 1.7$ & & $9.8 \pm 5.5$ & \\
\hline \multicolumn{5}{|l|}{ Pulmonary function } \\
\hline FVC L & $5.12 \pm 0.35$ & $106 \pm 3$ & $4.34 \pm 0.28^{*}$ & $92 \pm 5^{*}$ \\
\hline FEV 1 L & $4.27 \pm 0.30$ & $112 \pm 3$ & $3.31 \pm 0.32^{\star}$ & $90 \pm 8^{*}$ \\
\hline $\mathrm{FEV}_{1} / \mathrm{FVC} \%$ & $83.2 \pm 1.6$ & & $74.8 \pm 4.3^{*}$ & \\
\hline PEFR $L \cdot S^{-1}$ & $9.95 \pm 0.43$ & $94 \pm 3$ & $7.90 \pm 0.79 *$ & $76 \pm 7^{\star}$ \\
\hline FEF $25-75 \% L \cdot s^{-1}$ & $6.12 \pm 0.29$ & $127 \pm 4$ & $4.39 \pm 0.52^{\star}$ & $93 \pm 10^{*}$ \\
\hline IC L & $4.21 \pm 0.24$ & $107 \pm 4$ & $4.00 \pm 0.33$ & $92 \pm 7$ \\
\hline EELV L & $0.91 \pm 0.22$ & & $0.34 \pm 0.09^{*}$ & \\
\hline \multicolumn{5}{|l|}{ Peak exercise } \\
\hline$V^{\prime} \mathrm{O}_{2}, \max L \cdot \min ^{-1}$ & $2.87 \pm 0.34$ & $100 \pm 14$ & $1.79 \pm 0.16^{*}$ & $53 \pm 7^{*}$ \\
\hline Peak power W & $228 \pm 30$ & & $127 \pm 10^{\star}$ & \\
\hline$f \mathrm{c}$, max beats $\cdot \mathrm{min}^{-1}$ & $156 \pm 9$ & $94 \pm 4$ & $106 \pm 6^{\star}$ & $68 \pm 3^{*}$ \\
\hline$V^{\prime} E, \max L \cdot \min ^{-1}$ & $146.0 \pm 16.0$ & & $80 \pm 4.7^{*}$ & \\
\hline Wb,tot,peak J.min ${ }^{-1}$ & $485 \pm 107$ & & $190 \pm 9^{*}$ & \\
\hline
\end{tabular}

Data are presented as mean \pm SEM, unless otherwise stated. \% pred: \% predicted; BMI: body mass index; FVC: forced vital capacity; FEV1: forced expiratory volume in $1 \mathrm{~s}$; PEFR: peak expiratory flow rate; FEF25-75\%: forced expiratory flow at $25-75 \%$ of FVC; IC: inspiratory capacity; EELV: end-expiratory lung volume; $V^{\prime} \mathrm{O}_{2}$,max: maximal oxygen uptake; $f \mathrm{C}$,max: maximal cardiac frequency; $V^{\prime} E$,max: maximal minute ventilation; Wb,tot,peak: total work of breathing at peak exercise; IDC: idiopathic dilated cardiomyopathy; CAD: coronary artery disease. ${ }^{*}: p<0.05$ compared with control group. 
TABLE 2 Timing and pattern of breathing during graded exercise in patients with heart failure (HF) and control subjects

\begin{tabular}{|c|c|c|c|c|c|c|c|c|}
\hline & \multicolumn{2}{|c|}{$V^{\prime}$ E $20 \mathrm{~L} \cdot \mathrm{min}^{-1}$} & \multicolumn{2}{|c|}{$V^{\prime} E 40 \mathrm{~L} \cdot \mathrm{min}^{-1}$} & \multicolumn{2}{|c|}{$V^{\prime}$ E $60 \mathrm{~L} \cdot \mathrm{min}^{-1}$} & \multicolumn{2}{|c|}{$V^{\prime}$ E $80 \mathrm{~L} \cdot \mathrm{min}^{-1}$} \\
\hline & Control & HF & Control & HF & Control & HF & Control & HF \\
\hline VT L & $1.07 \pm 0.04$ & $1.03 \pm 0.06$ & $1.73 \pm 0.05$ & $1.59 \pm 0.07^{\star}$ & $2.27 \pm 0.05$ & $2.02 \pm 0.11^{*}$ & $2.63 \pm 0.10$ & $2.19 \pm 0.16^{*}$ \\
\hline$f R$ breaths $\cdot \mathrm{min}^{-1}$ & $20.8 \pm 0.9$ & $21.9 \pm 1.2$ & $23.4 \pm 0.7$ & $25.5 \pm 1^{*}$ & $27.0 \pm 0.9$ & $30.0 \pm 1.4^{\star}$ & $30.8 \pm 1.3$ & $34.9 \pm 1.9^{*}$ \\
\hline$t \mid s$ & $1.27 \pm 0.08$ & $1.12 \pm 0.08$ & $1.20 \pm 0.06$ & $1.03 \pm 0.05^{\star}$ & $1.06 \pm 0.05$ & $0.90 \pm 0.06^{*}$ & $0.94 \pm 0.05$ & $0.79 \pm 0.05^{\star}$ \\
\hline$V T / t \mathbf{L} L \cdot \mathbf{s}^{-1}$ & $0.85 \pm 0.03$ & $0.93 \pm 0.03$ & $1.46 \pm 0.04$ & $1.54 \pm 0.03$ & $2.17 \pm 2.26$ & $2.26 \pm 0.03$ & $2.82 \pm 0.06$ & $2.73 \pm 0.12$ \\
\hline$V T / t E L \cdot s^{-1}$ & $0.62 \pm 0.02$ & $0.59 \pm 0.02$ & $1.22 \pm 0.02$ & $1.14 \pm 0.02^{*}$ & $1.89 \pm 0.03$ & $1.75 \pm 0.04^{*}$ & $2.52 \pm 0.04$ & $2.47 \pm 0.15$ \\
\hline
\end{tabular}

Data are presented as mean \pm SEM. $V^{\prime} E$ : minute ventilation; $V T$ : tidal volume; $f R$; respiratory frequency; $t I$ : inspiratory time; $t E$ : expiratory time; ttot: total time of respiratory cycle. *: $p<0.05$ compared with control group.

Furthermore, the overall higher mechanical cost of breathing in these patients appears to be due to greater amounts of resistive rather than elastic respiratory muscle work. The greater resistive $\mathrm{Wb}$ in HF patients most probably reflects an increase in airways and lung tissue resistance. However, the marginally higher inspiratory elastic $W \mathrm{~b}$ observed in these patients was related to a combined decrease in the compliances of the lungs and chest wall.

\section{Wb in $H F$}

In 1934, CHRISTIE and MEAKINS [29] were the first to provide direct evidence that patients with congestive HF often present with an impaired distensibility of the lungs (i.e. CL,dyn). Since then, other ventilatory derangements have been described in this population, ranging from restrictive-obstructive disorders in pulmonary function to functional weakness of the respiratory
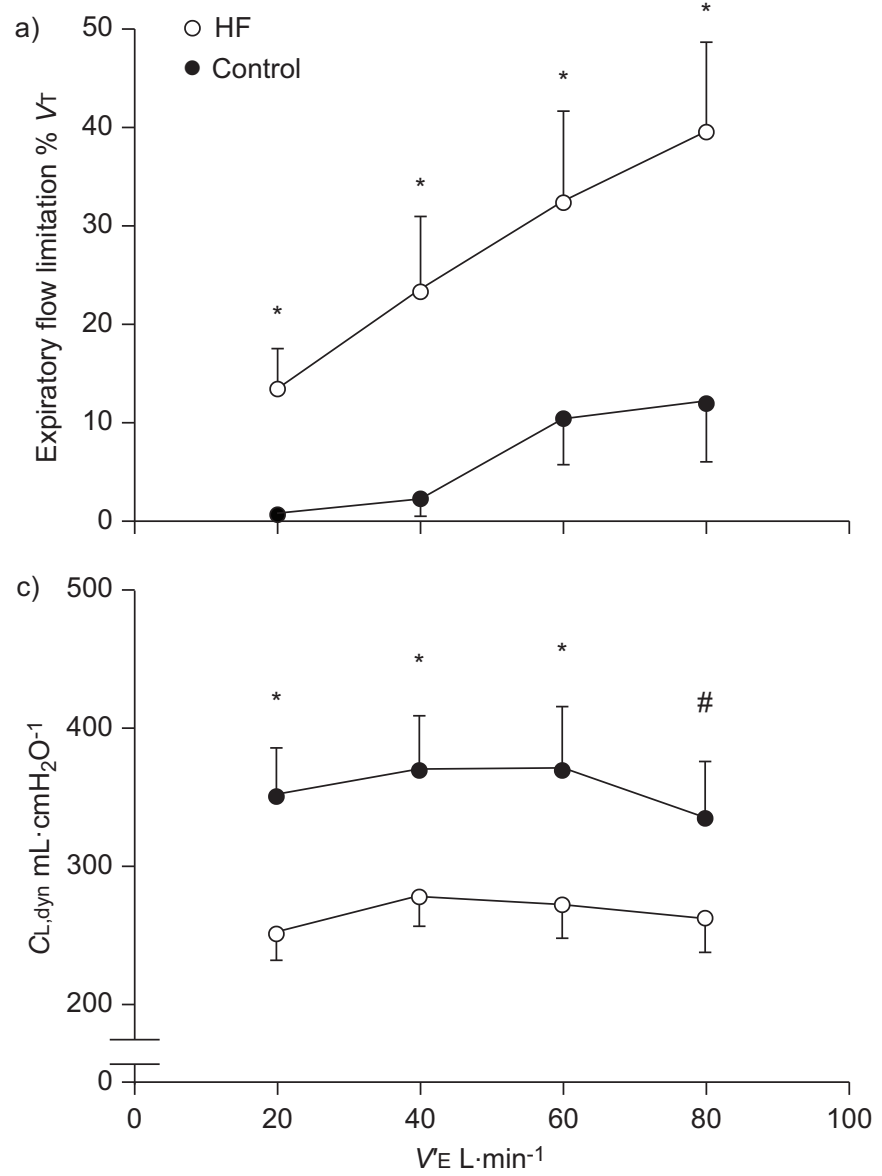

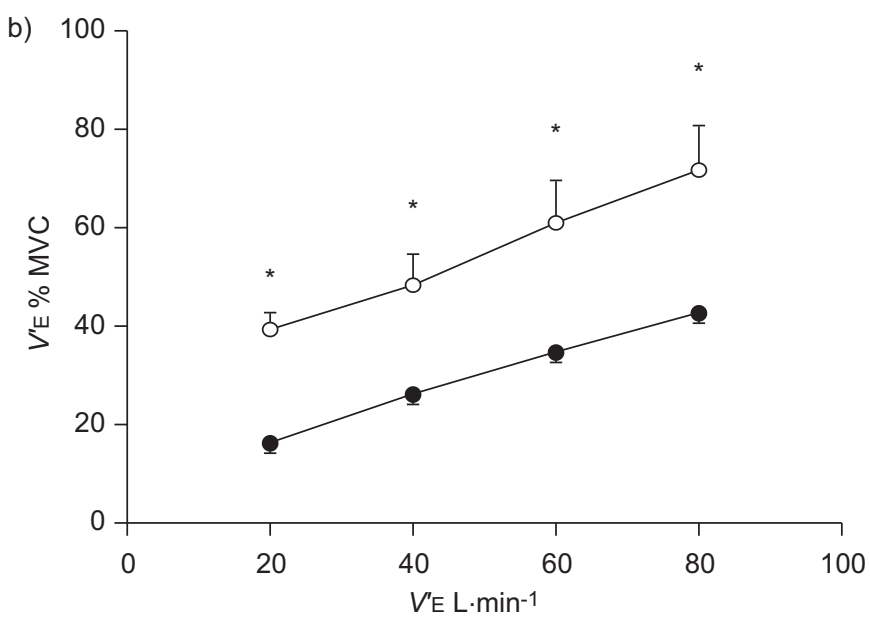

FIGURE 1. Ventilatory constraint during graded exercise in patients with heart failure (HF) and healthy control subjects. a) Expiratory flow limitation. b) Minute ventilation ( $\left.V^{\prime} E\right)$. c) Dynamic lung compliance (CL,dyn). Data are presented as mean \pm SEM. VT: tidal volume; MVC: maximal ventilatory capacity. ${ }^{*}: p<0.05$ compared with control group. \#: $p=0.09$ compared with control group. 


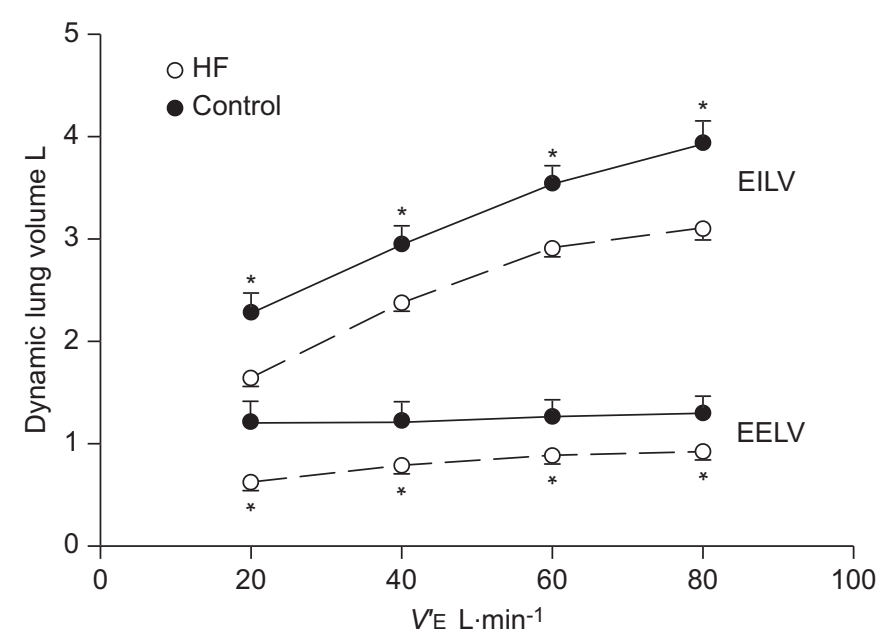

FIGURE 2. Dynamic lung volumes during graded exercise in patients with heart failure (HF) and healthy control subjects. The dynamic lung volumes of patients with chronic $\mathrm{HF}$ were systematically lower during the graded exercise test compared with the control group. Data are presented as mean \pm SEM. EILV: endinspiratory lung volume; EELV: end-expiratory lung volume; $V^{\prime} E$ : minute ventilation. *: $p<0.05$ compared with control group.

muscles and the development of severe ventilatory constraint during physical activity [14, 30-34]. These pathologies would together serve to increase the amount of work performed by the respiratory muscles per breath. Many investigators have provided support for this rationale using surrogate measures of the $W \mathrm{~b}$, such as the pressure-time and tension-time indices of $P$ oes and diaphragmatic pressure traces during exercise in patients with HF [30, 35, 36]. It should be noted that these parameters are not indicative of respiratory muscle work per se, but rather provide an index of respiratory muscle blood flow and oxygen uptake $[37,38]$. Others have determined the $\mathrm{Wb}$ in HF patients using $P_{\text {oes }}-V \mathrm{~T}$ loops obtained during exercise $[8,9,11,39]$. However, these studies often neglected the elastic work incurred by movement of the chest wall and, therefore, may have underestimated the total $\mathrm{Wb}$ in these

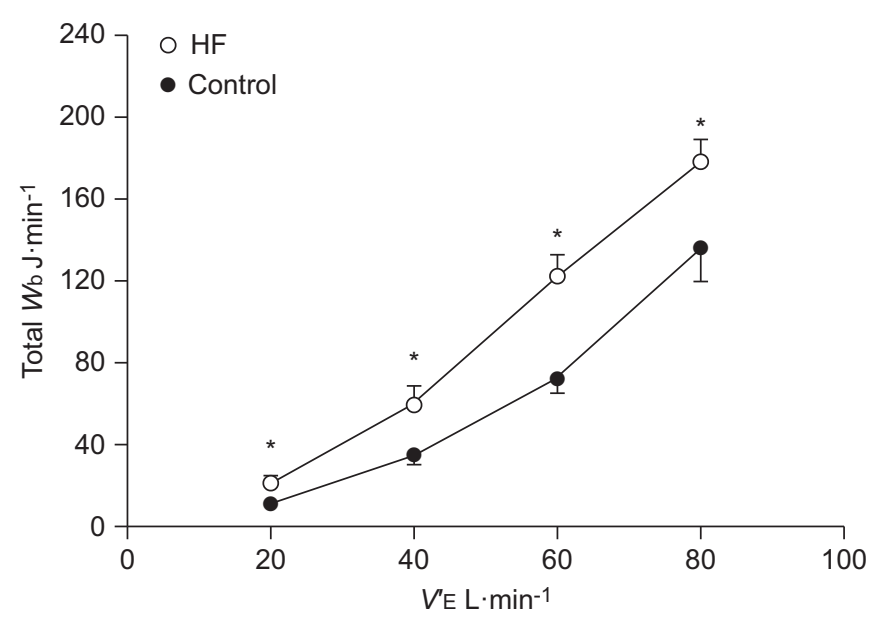

FIGURE 3. Total work of breathing (Wb) versus minute ventilation $\left(V^{\prime} E\right)$ during graded exercise in patients with heart failure (HF) and healthy control subjects. Data are presented as mean \pm SEM. *: $p<0.05$ compared with control group. patients. In the present study, we used the modified Campbell diagram to better quantify the overall $\mathrm{Wb}$ during exercise [27]. Figure 5 presents representative data from a HF patient and a healthy, age-matched control subject at a standardised $V^{\prime} \mathrm{E}$ of $\sim 80 \mathrm{~L} \cdot \mathrm{min}^{-1}$. It can be noted that all components of the $\mathrm{Wb}$ were appreciably greater for the HF patient compared to the control subject, except for the elastic work of expiration. These observations were characteristic of all HF patients over the range of $V^{\prime} \mathrm{E}$ investigated (fig. 4). Importantly, the systematically higher overall mechanical cost of breathing in HF patients appeared to be due to factors mediating an increase in the resistive, rather than the elastic, $W_{b}$ during graded exercise (fig. 6).

\section{Resistive Wb}

In agreement with previous observations [20, 31, 32, 34], the HF patients of the present study displayed relatively greater airway obstruction compared with the healthy control subjects (table 1). Hence, there appeared to be less reserve for HF patients to increase tidal flows before encroaching upon the mechanical constraints of the lungs during graded exercise (i.e. expiratory flow limitation). Dynamic lung volumes were also lower, positioning the HF patient's tidal breath over a range of lung volumes where maximal achievable expiratory flows are further reduced. Consequently, these patients displayed a greater degree of expiratory flow limitation, yielding slightly lower mean expiratory flows than control subjects at each level of $V^{\prime}$ E. Therefore, much of the greater expiratory resistive $W \mathrm{~b}$ observed in HF patients appears related to the generation of expiratory pressures far in excess of those required to produce maximal flows [40]. The inspiratory resistive $W b$ was also higher in HF patients compared with control subjects during graded exercise. However, this greater inspiratory resistive $\mathrm{Wb}$ was not accompanied by higher mean inspiratory flows, where faster flow rates would have caused a rise in dissipative pressure losses during inspiration. Instead, it is likely that inspiratory resistive $\mathrm{Wb}$ was greater in HF patients due to an increased pulmonary resistance. We interpret the above findings to represent an increased inspiratory and expiratory resistive load to breathing in HF patients during physical activity. Such an increased resistive load to breathing in HF patients may arise from the development (or progressive worsening) of pulmonary congestion and/or an increased bronchomotor tone during graded exercise $[8,19,41]$.

It can be reasoned that left systolic dysfunction leads to an increase in pulmonary capillary pressures, facilitating the transudation of fluid into the pulmonary interstitium [5, 42]. Pulmonary congestion is thought to increase airway resistance by reducing luminal diameter due to bronchial or pulmonary vessel engorgement, and/or by causing an imbalance of interfacial and radial forces acting on the airway wall itself [43-45]. Additionally, a rise in extraluminal pressure secondary to pulmonary congestion may promote the dynamic closure of dependent airways at relatively lower transmural pressures for any given lung volume during expiration (i.e. the Starling resistor model), although this enhanced airway collapsibility would seemingly be offset by an increased bronchomotor tone. Indeed, there is cause to believe that pulmonary interstitial oedema leads to the development of airway hyperresponsivity in HF patients ("cardiac asthma") [45, 46]. An increased 

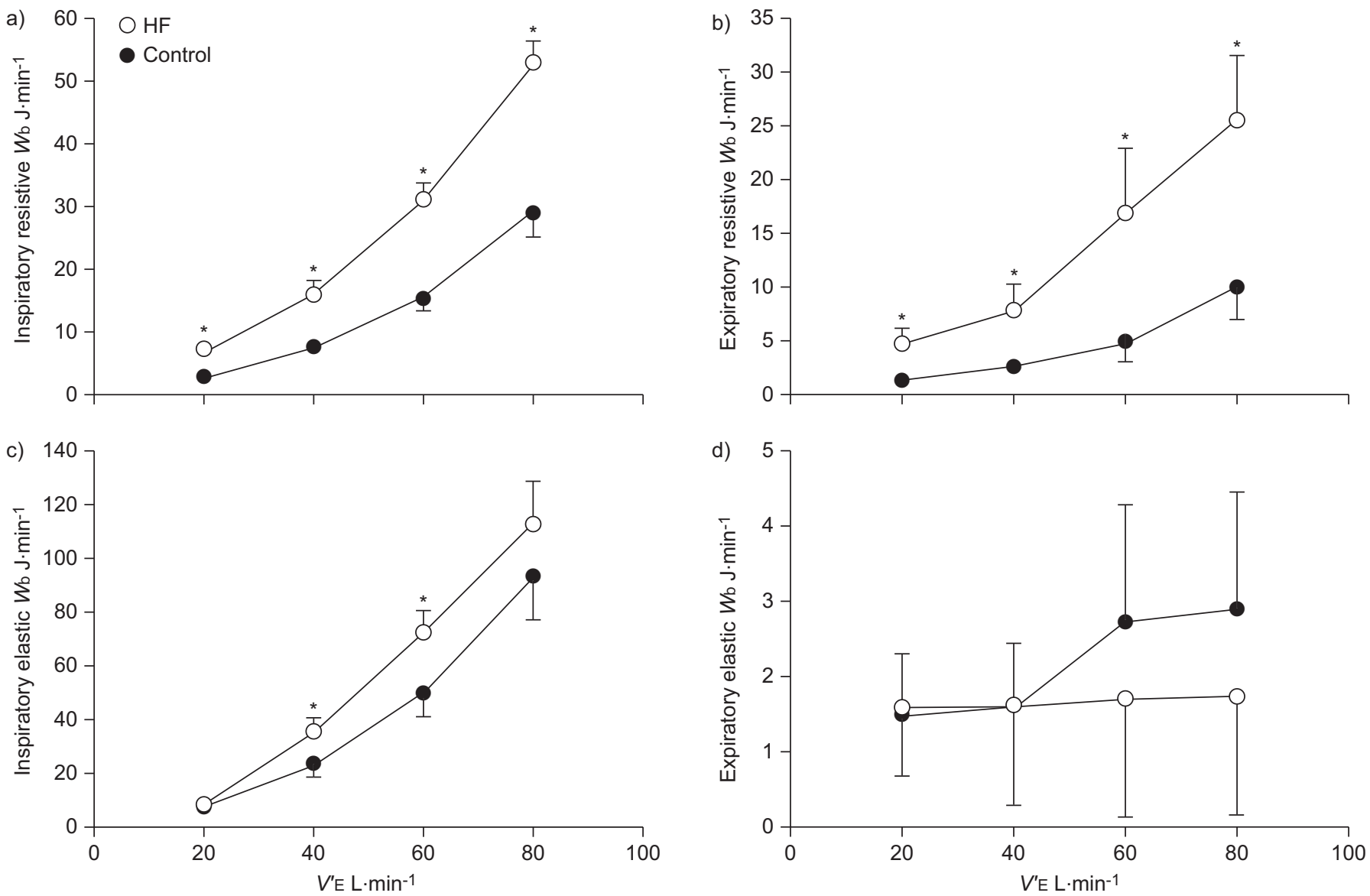

FIGURE 4. $a, b)$ Resistive and $c$, d) elastic work of breathing (Wb) versus minute ventilation ( $\left.V^{\prime} E\right)$ during graded exercise in patients with heart failure (HF) and healthy control subjects. a, c) Inspiratory. b, d) Expiratory. Data are presented as mean \pm SEM. *: $p<0.05$ compared with control group.

Pressure points of zero flow during tidal breath

- Recoil pressures of the chest wall at points of zero flow during the tidal breath

$\square$ Inspiratory resistive $W_{\mathrm{b}} \quad \square$ Expiratory resistive $W_{\mathrm{b}}$

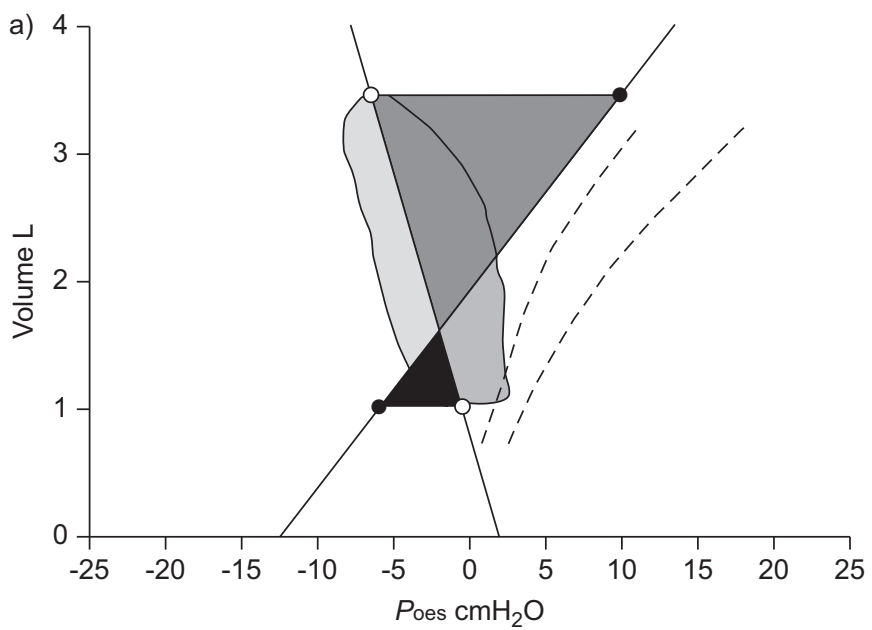

b)

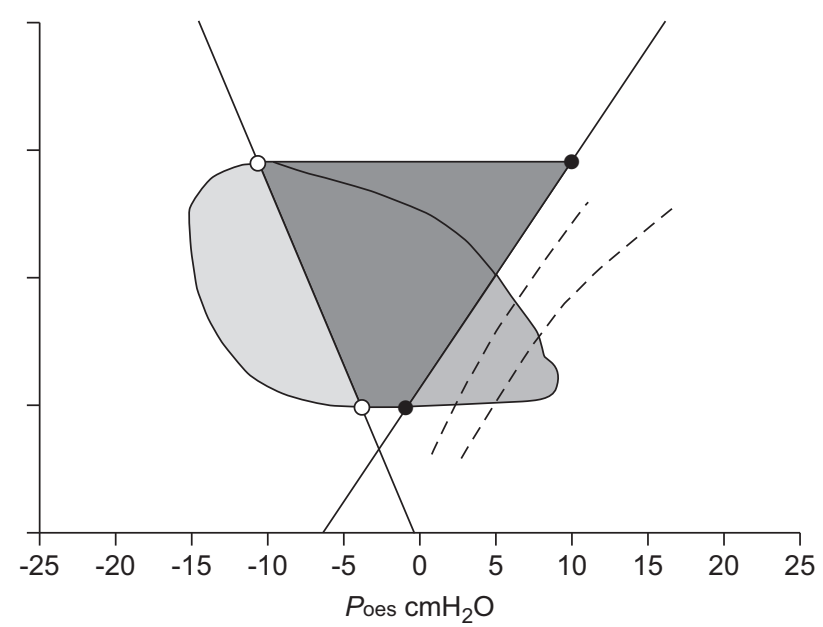

FIGURE 5. The resistive and elastic work of breathing $(\mathrm{Wb})$ in a) a healthy control subject (age $71 \mathrm{yrs}$; body mass $78.0 \mathrm{~kg}$; minute ventilation $80.5 \mathrm{~L} \cdot \mathrm{min}^{-1}$ ) and b) a patient with heart failure (New York Heart Association functional class II; ejection fraction 25\%; age 73 yrs; body mass $96.4 \mathrm{~kg}$; V'E $80.4 \mathrm{~L} \cdot \mathrm{min}^{-1}$ ) during graded exercise. Poes: oesophageal pressure. 
Inspiratory resistive $W_{\mathrm{b}} \quad \square$ Expiratory resistive $W_{\mathrm{b}}$

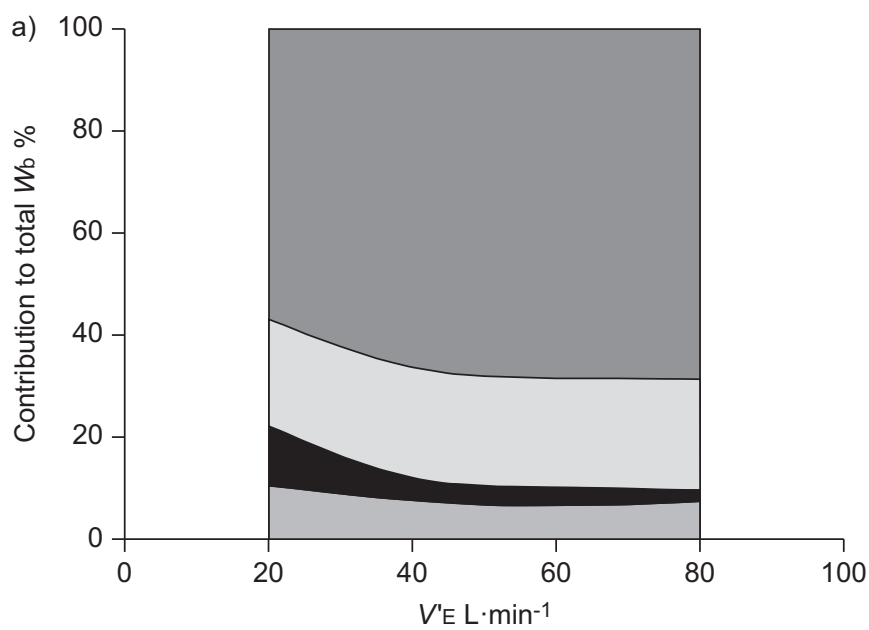

Inspiratory elastic $W_{b}$

Expiratory elastic $W_{b}$

b)

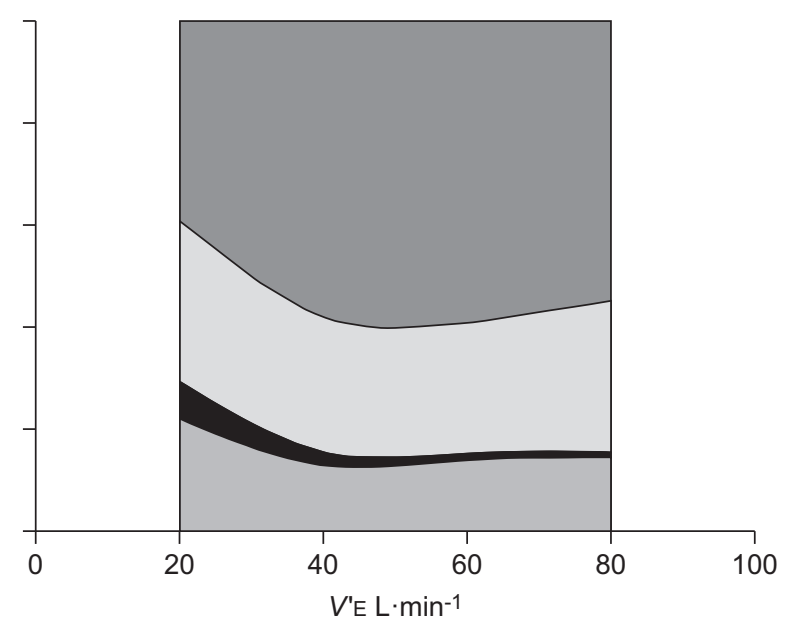

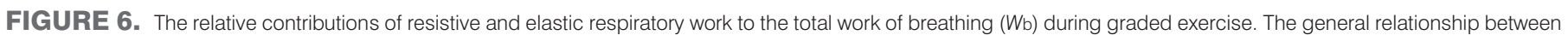

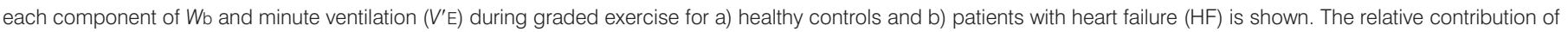
inspiratory and expiratory resistive Wb to the total mechanical cost of breathing appears larger for HF patients than control subjects during graded exercise.

bronchomotor tone during exercise may promote "buckling" of the airway mucosa (particularly during expiration) and would certainly increase the resistance of the airways during spontaneous breathing. It should be noted that our measurement of the resistive $\mathrm{Wb}$ included the pressures lost to hysteresivity of the lung tissue itself. Importantly, the resistance of lung tissue increases when the pulmonary interstitium becomes oedematous and during instances of increased bronchomotor tone [47-49]. Therefore, it is reasonable to suggest that pulmonary congestion, either through primary or secondary influences, may lead to an increase in both airway and tissue resistance of the lungs, thereby increasing the resistive load to breathing in patients with HF during exercise.

\section{Elastic Wb}

Overall, HF patients displayed a more rapid, shallow breathing pattern for any given level $V^{\prime} \mathrm{E}$ than control subjects. This "exercise tachypnoea" is a hallmark of the disease and appears inversely related to $C \mathrm{~L}$,dyn during exercise [14]. Our data are consistent with these observations in that $V \mathrm{~T}$ and $\mathrm{CL}$,dyn were systematically lower, and $f R$ higher, in HF patients than control subjects during graded exercise (table 2 and fig. 1). It can be reasoned that patients with HF adopt a rapid, shallow breathing pattern at relatively lower operational lung volumes to avoid a high elastic $W b$ due to increased lung stiffness. In spite of these efforts, the lower compliances of the lungs and chest wall in these patients produced a higher inspiratory elastic $\mathrm{Wb}$ compared with control subjects during exercise (figs 4 and 5); the expiratory elastic $W \mathrm{~b}$ was negligible in both groups.

The reduction in $\mathrm{CL}_{\mathrm{L}}$ dyn observed in HF patients may be attributed to a number of mechanisms: the competition between lung and cardiac tissue for intrathoracic space (e.g. cardiomegaly); the erectile nature of an engorged pulmonary and/or bronchial vasculature; the development of pulmonary interstitial oedema, particularly during exercise; and remodelling of the lung parenchyma due to elevated circulating cytokines and/ or chronic hydrostatic insult [18, 41, 50-52]. Although the mechanisms for the lower $C_{\mathrm{L}}$,dyn have been well described in $\mathrm{HF}$, we also noted that compliance of the chest wall in these patients was lower $(\sim 18 \%)$ than in control subjects. To the best of our knowledge, the later observation has not been reported in unanaesthetised patients with stable HF. The reasons for such increased stiffness of the chest wall in this population are unclear. Evidence suggests that subject anthropometric characteristics do not adequately explain the differences in the compliance of the chest wall between individuals $[53,54]$. Thus, it is unlikely that chest wall compliance was lower in the HF group due to the larger body mass and BMI of the patients. In addition, we controlled for the age-related decline in chest wall compliance [54] by comparing HF patients to healthy, agematched individuals. At present, the precise mechanisms that cause the decline in chest wall compliance in patients with stable $\mathrm{HF}$ require further investigation.

\section{Interrelationships between resistive and elastic $\mathbf{W}_{b}$}

We caution the reader that although each component of the $\mathrm{Wb}$ has been treated separately in this discussion, we do not imply any degree of isolation between parameters. The mechanisms that affect an increase in the resistive $W \mathrm{~b}$ are likely to influence the elastic $W \mathrm{~b}$ and vice versa. As mentioned earlier, continued pulmonary congestion may lead to airway hyperresponsiveness in patients with HF [45, 46]. Bronchomotor tone not only regulates airway and lung tissue resistance but also determines the dynamic elastance of the bronchial tree $[55,56]$. For example, when the smooth muscle layer of the airways contracts, tension develops in the radial and longitudinal axes of the bronchial tree; this tension increases the amount of respiratory muscle force required to expand the dimensions of the lungs along these planes during inspiration. Indeed, recent evidence suggests that relaxation of airway smooth muscle via inhalation of short-acting bronchodilators decreases both pulmonary resistance and elastance in patients with HF [19]. Thus, with respect to our data, an increased bronchomotor tone may, therefore, have contributed to the decreased $C_{L}$,dyn observed in HF patients during graded exercise. 


\section{Implications and clinical significance}

The heightened $\mathrm{Wb}$ observed in HF patients necessitates greater oxygen delivery to the respiratory muscles during exercise, which is clearly an issue for patients with an already reduced cardiac reserve. Therefore, the respiratory muscles may compete with locomotor muscles for cardiac output during physical activity, thereby impairing the ability of these patients to perform the activities of daily living. Indeed, oxygen delivery to the locomotor muscles increases and tolerance to physical activity improves when the $\mathrm{Wb}$ is unloaded in $\mathrm{HF}$ patients during submaximal exercise [11-13, 57]. These findings, in conjunction with the observations of the present study, emphasise the importance of targeting respiratory symptoms in the management of patients with HF.

\section{Methodological considerations}

We used the modified Campbell diagram to quantify the resistive and elastic components of the $W \mathrm{~b}$ during exercise. Although this approach has been used widely in the past [58-60], the technique is not without its limitations. Our measurements of the total $\mathrm{Wb}$ did not include the additional mechanical cost incurred by deformation of the chest wall, hysteresivity of chest wall tissues, eccentric (negative) and/or isometric work performed by the respiratory muscles, compression of thoracic gas and the work done on the abdominal viscera $[59,61]$. Therefore, the modified Campbell diagram may have underestimated the true mechanical cost of breathing in our subjects. It should be remembered that chest wall compliance was lower and the degree of expiratory flow limitation, during exercise, was higher for HF patients than control subjects. Accordingly, the amount of respiratory muscle work lost to the hysteresivity and deformation of the chest wall, and to thoracic gas compression, should necessarily be higher in patients with HF. If these sources of respiratory muscle work were accounted for in the present study, the differences in the $\mathrm{Wb}$ observed between groups would most probably be accentuated rather than diminished.

The HF patients of the present study were, on average, heavier than control subjects (table 1). Although it is reasonable to suggest that obesity may have contributed to the differences in respiratory variables between groups (i.e. HF versus controls), entering participants' mass as a covariate into the analyses of variances performed in this study did not alter the significance of our findings (i.e. our observations cannot be adequately explained by differences in subject anthropometric characteristics between groups). However, it is worth noting that there were a greater number of ex-smokers among the HF patients than the healthy, age-matched control subjects (four out of nine patients versus two out of nine controls). Smoking history was also relatively greater in HF patients than control subjects, although this comparison was not significant. It is possible that smoking-related decrements in airway calibre may have accounted for some of the obstructive changes observed in the patients with HF [34].

\section{Conclusions}

We report that the total $\mathrm{Wb}$ is systematically higher in HF patients than control subjects at standardised $V^{\prime} \mathrm{E}$ during physical activity. Importantly, we have shown that the inordinately higher $W_{b}$ in HF patients is primarily due to a greater resistive load of breathing. Specifically, HF patients adopt a rapid, shallow breathing pattern at relatively low lung volumes in an effort to avoid high levels of inspiratory elastic $W b$. This breathing strategy comes at the expense of greater ventilatory constraint, expiratory flow limitation and, therefore, an increased expiratory resistive $W \mathrm{~b}$. The reasons for the higher inspiratory resistive $W \mathrm{~b}$ in $\mathrm{HF}$ patients are uncertain, but may involve an increase in both airway and tissue resistance of the lungs, secondary to the development (or worsening) of pulmonary congestion, and/or increased bronchomotor tone during exercise. The mechanisms responsible for the relatively lower compliance of the chest wall in HF patients remain unclear. Overall, the ventilatory derangements observed in patients with $\mathrm{HF}$ affect an increase in the mechanical (and, therefore, oxygen) cost of breathing at any given $V^{\prime} \mathrm{E}$ when compared with healthy, age-matched control subjects during exercise. These findings contribute to the growing impetus for research examining the respiratory complications associated with $\mathrm{HF}$.

\section{SUPPORT STATEMENT}

This work was supported by the National Institutes of Health grant HL 71478 to B.D. Johnson.

\section{STATEMENT OF INTEREST}

None declared.

\section{ACKNOWLEDGEMENTS}

The authors of the present study would like to thank K. O'Malley, M. Hulsebus and A. Miller (Division of Cardiovascular Diseases, Mayo Clinic, Rochester, MN, USA) for their assistance in subject recruitment and data collection.

\section{REFERENCES}

1 Esposito F, Mathieu-Costello O, Shabetai R, et al. Limited maximal exercise capacity in patients with chronic heart failure: partitioning the contributors. J Am Coll Cardiol 2010; 55: 1945-1954.

2 Drexler H, Riede U, Munzel T, et al. Alterations of skeletal muscle in chronic heart failure. Circulation 1992; 85: 1751-1759.

3 Pina IL, Apstein CS, Balady GJ, et al. Exercise and heart failure: a statement from the American Heart Association Committee on Exercise, Rehabilitation, and Prevention. Circulation 2003; 107: 1210-1225.

4 Johnson RL Jr. Gas exchange efficiency in congestive heart failure II. Circulation 2001; 103: 916-918.

5 Gehlbach BK, Geppert E. The pulmonary manifestations of left heart failure. Chest 2004; 125: 669-682.

6 Mancini DM. Pulmonary factors limiting exercise capacity in patients with heart failure. Prog Cardiovasc Dis 1995; 37: 347-370.

7 Mandak JS, McConnell TR. Pulmonary manifestations of chronic heart failure. J Cardiopulm Rehabil 1998; 18: 89-93.

8 Hayward GW, Knott JM. The effect of exercise on lung distensibility and respiratory work in mitral stenosis. Br Heart $J$ 1955; 17: 303-311.

9 Christie RV. Dyspnoea in relation to the visco-elastic properties of the lung. Proceedings of the Proc $R$ Soc Med 1953; 46: 381-386.

10 Dempsey JA. Cardiorespiratory responses to exercise in CHF: a conspiracy of maladaptation. J Physiol 2010; 588: 2683.

11 Olson TP, Joyner MJ, Dietz NM, et al. Effects of respiratory muscle work on blood flow distribution during exercise in heart failure. J Physiol 2010; 588: 2487-2501.

12 O'Donnell DE, D'Arsigny C, Raj S, et al. Ventilatory assistance improves exercise endurance in stable congestive heart failure. $A m$ J Respir Crit Care Med 1999; 160: 1804-1811.

13 Mancini D, Donchez L, Levine S. Acute unloading of the work of breathing extends exercise duration in patients with heart failure. J Am Coll Cardiol 1997; 29: 590-596. 
14 Agostoni P, Pellegrino R, Conca C, et al. Exercise hyperpnea in chronic heart failure: relationships to lung stiffness and expiratory flow limitation. J Appl Physiol 2002; 92: 1409-1416.

15 Ries AL, Gregoratos G, Friedman PJ, et al. Pulmonary function tests in the detection of left heart failure: correlation with pulmonary artery wedge pressure. Respiration 1986; 49: 241-250.

16 Dimopoulou I, Daganou M, Tsintzas OK, et al. Effects of severity of long-standing congestive heart failure on pulmonary function. Respir Med 1998; 92: 1321-1325.

17 Waxman AB. Pulmonary function test abnormalities in pulmonary vascular disease and chronic heart failure. Clin Chest Med 2001; 22: $751-758$

18 Olson TP, Beck KC, Johnson BD. Pulmonary function changes associated with cardiomegaly in chronic heart failure. J Card Fail 2007; 13: 100-107.

19 Witte KKA, Morice A, Cleland JGF, et al. The reversibility of increased airways resistance in chronic heart failure measured by impulse oscillometry. J Card Fail 2004; 10: 149-154.

20 Witte KK, Morice A, Clark AL, et al. Airway resistance in chronic heart failure measured by impulse oscillometry. J Card Fail 2002; 8: 225-231.

21 Baydur A, Behrakis PK, Zin WA, et al. A simple method for assessing the validity of the esophageal balloon technique. Am Rev Respir Dis 1982; 126: 788-791.

22 Guenette JA, Dominelli PB, Reeve SS, et al. Effect of thoracic gas compression and bronchodilation on the assessment of expiratory flow limitation during exercise in healthy humans. Respir Physiol Neurobiol 2010; 170: 279-286.

23 Babb TG, Rodarte JR. Estimation of ventilatory capacity during submaximal exercise. J Appl Physiol 1993; 74: 2016-2022.

24 Johnson BD, Scanlon PD, Beck KC. Regulation of ventilatory capacity during exercise in asthmatics. J Appl Physiol 1995; 79: 892-901.

25 Olafsson S, Hyatt RE. Ventilatory mechanics and expiratory flow limitation during exercise in normal subjects. J Clin Invest 1969; 48 564-573.

26 Rahn H, Otis AB, Chadwick LE, et al. The pressure-volume diagram of the thorax and lung. Am J Physiol 1946; 146: 161-178.

27 Roussos C, Campbell EJM. Respiratory muscle energetics. In: Macklem PT, Mead J, eds. Handbook of Physiology. Bethesda, American Physiological Society, 1986; pp. 481-509.

28 Salome CM, King GG, Berend N. Physiology of obesity and effects on lung function. J Appl Physiol 2010; 108: 206-211.

29 Christie RV, Meakins JC. The intrapleural pressure in congestive heart failure and its clinical significance. J Clin Invest 1934; 13: 323-345.

30 Mancini D, Henson D, LaManca J, et al. Respiratory muscle function and dyspnea in patients with chronic congestive heart failure. Circulation 1992; 86: 909-918.

31 Johnson $\mathrm{BD}$, Beck $\mathrm{KC}$, Olson LJ, et al. ventilatory constraints during exercise in patients with chronic heart failure. Chest 2000; 117: 321-332.

32 Daganou M, Dimopoulou I, Alivizatos PA, et al. Pulmonary function and respiratory muscle strength in chronic heart failure: comparison between ischaemic and idiopathic dilated cardiomyopathy. Heart 1999; 81: 618-620.

33 Hammond MD, Bauer KA, Sharp JT, et al. Respiratory muscle strength in congestive heart failure. Chest 1990; 98: 1091-1094.

34 Johnson BD, Beck KC, Olson LJ, et al. Pulmonary function in patients with reduced left ventricular function. Chest 2001; 120: 1869-1876.

35 Mancini DM, La Manca J, Donchez L, et al. The sensation of dyspnea during exercise is not determined by the work of breathing in patients with heart failure. J Am Coll Cardiol 1996; 28: 391-395.

36 Kufel TJ, Pineda LA, Junega RG, et al. Diaphragmatic function after intense exercise in congestive heart failure patients. Eur Respir J 2002; 20: 1399-1405.

37 Field S, Sanci S, Grassino A. Respiratory muscle oxygen consumption estimated by the diaphragm pressure-time index. J Appl Physiol 1984; 57: 44-51.
38 Hussain SN, Roussos C, Magder S. Effects of tension, duty cycle, and arterial pressure on diaphragmatic blood flow in dogs. J Appl Physiol 1989; 66: 968-976.

39 Marshall R, Mcllroy MB, Christie RV. The work of breathing in mitral stenosis. Clin Sci (Lond) 1954; 13: 137-146.

40 Hyatt RE, Flath RE. Relationship of air flow to pressure during maximal respiratory effort in man. J Appl Physiol 1966; 21: 477-482.

41 Agostoni $\mathrm{P}$, Cattadori G, Bianchi $\mathrm{M}$, et al. Exercise-induced pulmonary edema in heart failure. Circulation 2003; 108: 2666-2671.

42 Wasserman K, Zhang YY, Gitt A, et al. Lung function and exercise gas exchange in chronic heart failure. Circulation 1997; 96: 2221-2227.

43 Wetzel RC, Herold CJ, Zerhouni EA, et al. Intravascular volume loading reversibly decreases airway cross-sectional area. Chest 1993; 103: 865-870.

44 Pellegrino R, Dellacà R, Macklem PT, et al. Effects of rapid saline infusion on lung mechanics and airway responsiveness in humans. J Appl Physiol 2003; 95: 728-734.

45 Cabanes LR, Weber SN, Matran R, et al. Bronchial hyperresponsiveness to methacholine in patients with impaired left ventricular function. N Engl J Med 1989; 320: 1317-1322.

46 Sasaki F, Ishizaki T, Mifune J, et al. Bronchial hyperresponsiveness in patients with chronic congestive heart failure. Chest 1990; 97: 534-538.

47 Barnas GM, Sprung J, Kahn R, et al. Lung tissue and airway impedances during pulmonary edema in normal range of breathing. J Appl Physiol 1995; 78: 1889-1897.

48 Kaczka DW, Ingenito EP, Suki B, et al. Partitioning airway and lung tissue resistances in humans: effects of bronchoconstriction. J Appl Physiol 1997; 82: 1531-1541.

49 Lutchen KR, Suki B, Zhang Q, et al. Airway and tissue mechanics during physiological breathing and bronchoconstriction in dogs. J Appl Physiol 1994; 77: 373-385.

50 Milani RV, Mehra MR, Lavie CJ, et al. The clinical relevance of circulating tumor necrosis factor- $\alpha$ in acute decompensated chronic heart failure without cachexia. Chest 1996; 110: 992-995.

51 Ebert RV. The lung in congestive heart failure. Arch Intern Med 1961; 107: 450-459.

52 Ceridon ML, Morris NR, Hulsebus ML, et al. Influence of bronchial blood flow and conductance on pulmonary function in stable systolic heart failure. Respir Physiol Neurobiol 2011; 177: 256-264.

53 Suratt PM, Wilhoit SC, Hsiao HS, et al. Compliance of chest wall in obese subjects. J Appl Physiol 1984; 57: 403-407.

54 Estenne M, Yernault JC, De Troyer A. Rib cage and diaphragmabdomen compliance in humans: effects of age and posture. J Appl Physiol 1985; 59: 1842-1848.

55 Mitzner W, Blosser S, Yager D, et al. Effect of bronchial smooth muscle contraction on lung compliance. J Appl Physiol 1992; 72: 158-167.

56 Shardonofsky FR, Officer TM, Boriek AM, et al. Effects of smooth muscle activation on axial mechanical properties of excised canine bronchi. J Appl Physiol 2001; 90: 1258-1266.

57 Borghi-Silva A, Carrascosa C, Oliveira CC, et al. Effects of respiratory muscle unloading on leg muscle oxygenation and blood volume during high-intensity exercise in chronic heart failure. Am J Physiol Heart Circ Physiol 2008; 294: H2465-H2472.

58 Guenette JA, Querido JS, Eves ND, et al. Sex differences in the resistive and elastic work of breathing during exercise in endurancetrained athletes. Am J Physiol Regul Integr Comp Physiol 2009; 297: R166-R175.

59 Goldman MD, Grimby G, Mead J. Mechanical work of breathing derived from rib cage and abdominal V-P partitioning. I Appl Physiol 1976; 41: 752-763.

60 Dellweg D, Haidl P, Siemon K, et al. Impact of breathing pattern on work of breathing in healthy subjects and patients with COPD. Respir Physiol Neurobiol 2008; 161: 197-200.

61 Milic-Emili J, Orzalesi MM. Mechanical work of breathing during maximal voluntary ventilation. J Appl Physiol 1998; 85: 254-258. 